\title{
Factors associated with neck disorders among university student smartphone users
}

\author{
Suwalee Namwongsa ${ }^{\mathrm{a}, \mathrm{b}}$, Rungthip Puntumetakul ${ }^{\mathrm{a}, \mathrm{b}, *}$, Manida Swangnetr Neubert ${ }^{\mathrm{a}, \mathrm{c}}$ \\ and Rose Boucaut ${ }^{\mathrm{d}}$ \\ ${ }^{a}$ Research Center in Back, Neck and Other Joint Pain and Human Performance (BNOJPH), \\ Khon Kaen University, Khon Kaen, Thailand \\ ${ }^{\mathrm{b}}$ School of Physical Therapy, Faculty of Associated Medical Sciences, Khon Kaen University, \\ Khon Kaen, Thailand \\ ${ }^{\mathrm{c}}$ Program of Production Technology, Faculty of Technology, Khon Kaen University, Khon Kaen, Thailand \\ ${ }^{\mathrm{d}}$ School of Health Sciences (Physiotherapy) University of South Australia, iCAHE (International \\ Centre for Allied Health Evidence), Adelaide, Australia
}

Received 19 May 2017

Accepted 3 April 2018

\begin{abstract}
.
BACKGROUND: In our digital society, the use of smartphones has increased rapidly. Parallel with the growing use of smartphones, musculoskeletal problems associated with intensive smartphone use have also increased. Neck flexion is the most commonly adopted posture by smartphone users while looking at the visual display terminals of smartphones for extended periods; this posture may lead to neck disorders.

OBJECTIVE: The purpose of the current study was to investigate musculoskeletal disorders (MSDs) in smartphone users in Thailand in order to confirm high prevalence of neck pain. The study also aimed to determine all possible factors associated with neck disorders among smartphone users.

METHODS: A cross-sectional survey study was conducted with 779 undergraduate smartphone users. A self-administered questionnaire was used to collect self-report measures of smartphone use and musculoskeletal disorders. Descriptive statistics were used to analyze participant characteristics and the prevalence of musculoskeletal disorders. Logistic regression analysis was used to identify associated factors.

RESULTS: The most painful body region after the use of smartphones over a 12-month period was found to be the neck $(32.50 \%)$. Factors associated with neck disorders were a flexed neck posture (Odds Ratio $(\mathrm{OR}):=2.44,95 \%$ Confidence Interval $(\mathrm{CI})=1.21-4.90)$ and smoking (OR 8.99, 95\% CI 1.88-42.87).

CONCLUSIONS: The results suggest that to address neck disorders in smartphone users preventive initiatives should focus on reducing flexed neck postures and smoking.
\end{abstract}

Keywords: Prevalence, associated factors, neck flexion, smoking, pain

\section{Introduction}

In our digital society, the use of smartphones has increased rapidly. There are 3.4 billion smartphone users worldwide [1]. Thailand is nineteenth of the top

*Address for correspondence: Rungthip Puntumetakul. Tel.: +66 83419 6186; Fax: +66 4320 2399; E-mail: rungthiprt@ gmail. com. twenty-five countries worldwide in terms of smartphone use [2]. The age group of smartphone users varies, ranging from students and workers in their 20 s to senior citizens who are over the age of 60 [3]. University students in their 20s, in particular, use smartphones more than any other age group [4]. Compared to general cell phones, smartphones are very sophisticated devices, offering vast amounts of 
information and communication, all in the palm of your hand. They have an operating system, essentially making them palmtop computers, which are more powerful, provide greater computing capacity and diverse software applications [5]. Smartphones provide various conveniences, such as sending and receiving e-mail, accessing the Internet and engaging in entertainment, so the number of smartphone users has increased dramatically in recent years [6].

However, with the growing use of smartphones, comes concerns of increased musculoskeletal problems, which are associated with intensive smartphone usage. Musculoskeletal problems are among the most common occupational disorders in many countries and have an increasing trend [7]. An epidemiological study of 938 smartphone users conducted in the Republic of Korea found that $18.8 \%$ of smartphone users $(n=185)$ experienced musculoskeletal symptoms in at least one of their body parts [8]. In another Korean study involving 292 smartphone users, Kim et al. [6] found the most painful body regions from smartphones use were reported to be the neck $(55.8 \%)$ and shoulders (54.8\%) [9].

The results of a different study conducted in Asia with a similar survey method are from Hong Kong, where musculoskeletal disorders among smartphone users were shown to have a much higher prevalence than the Korean study conducted by Eom et al. [8]. In the Hong Kong study, $70 \%$ of respondents reported having experienced neck pain $(n=1,049), 65 \%$ had shoulder pain, $46 \%$ experienced wrist and finger pain, [10]; the reasons for the difference in the study results from Korea and Hong Kong are not clear, however, there was a considerable difference in the sample size. Nevertheless, in Thailand, musculoskeletal disorders among smartphone users, especially in university students who are in their 20s, have not yet been reported.

Previous studies have shown the risk of musculoskeletal symptoms in information technology device users, such as tablet users, is related to personal factors such as gender $(\mathrm{OR}=2.183,95 \%$ CI $[1.276$, 3.736], $p=0.004$ ) and awkward positions like sitting in a chair without back support $(\mathrm{OR}=2.821,95 \% \mathrm{CI}$ $[1.341,5.934], p=0.006)$ [11]. Both risk factors, gender and awkward postures, affected the prevalence of neck (84.6\%) and upper back/shoulder $(65.4 \%)$ musculoskeletal symptoms. While smartphone users have different usages compared with tablet users such as posture, previous studies which used self-report methods demonstrate four individual factors associated with musculoskeletal disorders in both groups. These factors were: (i) smartphone usage, people with higher smartphone use had more severe symptoms [12]; (ii) gender, females who use smartphones had a significantly higher neck disability index score than males ( $p<0.001)$ [13]; (iii) age of user, older persons and (iv) lack of exercise also increased the occurrence of musculoskeletal disorders [10].

Physical design factors related to the smartphone itself may also lead to smartphone users developing musculoskeletal disorders. These physical factors have been reported in many survey studies, includes: the size of smartphone liquid crystal displays $(n=292)$ [9], the number of text messages (relative risk $=1.425)(n=983)$, the time spent on daily usage of the smartphone (relative risk $=1.368$ ) $(n=2,353)[4,8]$ and prolonged static posture during smartphone usage $(n=1,049)$ [10]. Several studies have reported psychosocial factors associated with smartphone use. In Korea, Hwang et al. [12] surveyed the impact of smartphone overuse on upper extremity pain, anxiety, depression, and interpersonal relationships using several questionnaires (respectively: the Smartphone Addiction Inventory, the Musculoskeletal Symptom Checklist, the State-Trait Anxiety Inventory, the Beck Depression Inventory-II, and the Relationship Change Scale). They received 525 responses from college students and findings revealed anxiety and depression to be higher in the smartphone overuse group than in the normal use group [12]. In addition, Park et al. [14] studied depression using the Beck Depression Inventory (BDI) in "heavy" smartphone users, which they defined as those who spent 5.4 hours a day on their smartphone. Their sample consisted of 20 healthy student participants and the investigators reported that smartphone use could cause negative effects on a person's psychological status, such as depression $(p=0.006)$ [14].

Although it is clear that the neck is the area commonly reported to have the highest pain among smartphone users $[9,10]$, investigation on the ergonomic factors leading to neck pain among smartphone users remains limited [5]. Neck pain is known to be a multi factorial disorder, with head and spinal posture being one of the most important factors. Previous studies concluded that prolonged neck flexion is highly associated with neck pain both among the general population [15] and among office workers who use computers [16-18]. Similarly, the neck flexion posture is commonly adopted while smartphone users view the visual display terminals of smartphones for extended periods. Kang et al. [19] reported that this posture causes musculoskeletal problems [19]; however, the association between neck flexion during 
smartphone use and neck disability has not been scientifically confirmed to date. Furthermore, there are possible influential factors, which are reported to be associated with neck disorders in the general population, however, these have not been studied among smartphone users who smoke or suffer from stress.

The purpose of the current study was to investigate MSDs in smartphone users in Thailand in order to confirm high prevalence of neck pain. The study also aimed to determine all possible factors associated with neck disorders among smartphone users. The hypothesis was that ergonomic factors like neck postures are associated with neck disorders among smartphone users. The findings of this study can produce important information for exploring associations between intensive smartphone use and the occurrence of neck disorders. Additionally, the information may be used to underpin prevention and health promotion initiatives to address the risk of neck disorders associated with smartphone use.

\section{Methods}

\subsection{Study design}

This study used a cross-sectional design. A paperbased questionnaire was used to collect self-reported measures of smartphone use and self-reported musculoskeletal disorders in neck, shoulder, elbow, wrist and hand, upper back, lower back, hip and thigh, knee and ankle and foot. Data collection took place between August 1st, 2015 to January 30th, 2016. Prior to launching the study, human ethics approval was sought from the Khon Kean University. Informed consent was obtained from the subjects prior to completion of the self-administered questionnaire.

\subsection{Participants}

The sample of participants comprised 799 undergraduate students at Khon Kaen University, Thailand. The participants were recruited to the study by multistage random sampling. First, cluster sampling was used to randomly select 17 faculties in the Khon Kaen University, and then simple random sampling was used to select 47 students in each faculty. The exclusion criteria were: (1) graduate students, (2) unwilling participants and (3) obvious pre-existing musculoskeletal disorders which can be observed, such as joint deformity. Subjects without the exclusion criteria listed above were then asked to complete a questionnaire.

\subsection{Questionnaire}

The self-administered questionnaires were directly given to participants (face to face) in class. The questionnaire consisted of five sections which were: (1) demographic data (e.g. questions regarding sex, age, weight, height and other habits effecting health like smoking and exercise), (2) smartphone use data (e.g. questions regarding smartphone dimensions, data entry method, usage time and posture during use), (3) use of other devices data (e.g. questions regarding other devices usage type and usage time of other devices), (4) the Suanprung Stress Test-20 (e.g. questions regarding feelings of anxiety, dissatisfaction and confusion), and (5) the Thai language version of the Standardized Nordic Questionnaire (e.g. questions regarding aches, pains and discomfort in the neck within the last 12 months and the most frequent neck posture during smartphone use). The reliability and validity of the latter questionnaire was established in a pilot study (accepted as a high validity tool; validity (Index Of Consistency: IOC) $=0.6-1$ and accepted as a moderate reliability tool; reliability (Cronbach Alpha) $=0.71)[20]$.

The Suanprung stress test-20 (SPST-20) is used to assess the level of stress. Concurrent validity in the Thai population standardizes with electromyography (EMG) more than 0.27 (significant with 95\% CI). Cronbach's Alpha Reliability Coefficient of this test from a previous study is more than 0.7 with correlation to EMG significantly. This test is appropriate for students and adults. It is used to evaluate stress and interprets stress scores as follows: a score of 0 to 23 is defined as mild stress; a score of 24 to 41 is defined as moderate stress; a score of 42 to 61 is defined as high stress; and a score of 62 or more is defined as severe stress. The author further organizes this stress score into two categories. The first category indicates mild to moderate stress and the second category indicates high to severe stress [21].

A translated Thai language version of The Standardized Nordic Questionnaire (SNQ) is used to assess the prevalence of body part musculoskeletal discomfort within the last 7 days, last 12 months and to assess any trouble preventing normal work within the last 12 months. The SNQ is used to survey MSDs in the neck, shoulder, elbow, wrist and hand, upper back, lower back, hip and thigh, knee, ankle and foot. All answers are on a dichotomous scale (yes or no). 
Saetan et al in 2007 translated a Thai language version of the SNQ. Both its content validity and linguistic suitability were tested by 5 experts and 30 samples were used to test the inter rater reliability between rater. The reliability of the Thai language version was reported to be Kappa 0.66-1 [22]. Moreover, we gave posture choices in each of the body parts (neck, shoulder, elbow, wrist and hand, upper back, lower back, hip and thigh, knee, ankle and foot) followed by the Thai language version of the Standardized Nordic Questionnaire for smartphone users, asking them to describe their posture during smartphone use by indicating postures assumed by various body parts from a menu.

\subsection{Data analysis}

Descriptive statistics were used to analyze characteristics of participants and musculoskeletal disorder variables. Continuous variables were analyzed by mean and Standard Deviation (SD). The continuous variables included age, weight, height, study hours per day, years using smartphone, average hours using smartphone at a time and per day, years using other electronic devices, average time using other devices at a time and per day. Categorical variables were considered in terms of frequency and percentage. Categorical variables included: gender, Body Mass Index (BMI), hand dominance, smoking behavior, alcohol drinking behavior, exercise behavior, underlying disease, underlying musculoskeletal disorders, accident history, characteristics of smartphones used (namely model, brand etc.), stress, and musculoskeletal disorders. Simple logistic regression analysis was used to include each independent variable into a multiple logistic regression model; variables with a $p$-value less than 0.2 were included in the multiple logistic regression model. Multiple logistic regression analysis was performed using a stepwise regression process; variables with $p$-values of less than 0.05 were considered to be statistically significant. Data were analyzed using the STATA program version 10 (STATA, College Station, TX, USA).

\section{Results}

\subsection{Demographic information of the smartphone users who had musculoskeletal disorder}

All 799 students completed the questionnaire (i.e. $100 \%$ response rate). Responses from 643 of the 799 smartphone users met the inclusion criteria and these responses were analyzed. The general characteristics of the smartphone users who had musculoskeletal disorders are presented in Table 1 . There were 184 male $(28.62 \%)$ and 459 female $(71.38 \%)$ smartphone users who reported musculoskeletal disorders in this study. The majority of participants reported: a BMI value in the normal range $(89.74 \%)$, right hand dominance $(87.25 \%)$, no history of smoking $(93.78 \%)$ or drinking alcohol $(62.67 \%)$, currently engaged in exercise $(59.72 \%)$, no underlying disease $(81.80 \%)$, no underlying musculoskeletal disease $(98.29 \%)$ and no history of general accident (88.34\%) whereas some of them got only general accidents like contusion wound in upper and lower extremities (11.66\%). The average age of participants was $18.82 \pm 0.79$ years, weight was $55.95 \pm 10.83$ kilograms, height was $163.38 \pm 7.67$ centimeters and study hours per day was $6.03 \pm 1.49$. Almost half of the smartphone users who reported musculoskeletal disorders also reported high stress (43.08\%).

\subsection{Characteristics of smartphones used by respondents who reported musculoskeletal disorders $(n=643)$}

The characteristics of the smartphones used by participants who reported musculoskeletal disorders are presented in Table 2. The majority of the smartphone users who had musculoskeletal disorders used smartphone brand A (52.26\%), especially model A $(12.91 \%)$ with touch screen type (95.65\%). The dimensions of smartphones used had an average length of $133.24 \pm 12.50 \mathrm{~mm}$, average width of $66.99 \pm 7.32 \mathrm{~mm}$, average thickness of $8.28 \pm 1.28 \mathrm{~mm}$, average weight of $134.30 \pm 22.43$ gram, and average screen size of $4.46 \pm 0.69$ inches. Respondents reported they had used smartphones for $4.60 \pm 2.66$ years, used their smartphone $1.04 \pm 1.47$ hours per time and used it $5.03 \pm 3.37$ hours per day. Additionally, more than half the participants used smartphones in the evening (79.63\%) and they had rest time during use (93.62\%), both hands were used to hold the smartphone $(48.06 \%)$, and participants reported they entered data using both thumbs $(55.37 \%)$ in a sitting posture $(69.52 \%)$ for social network purpose such as Facebook and LINE applications (LINE application is a freeware application for instant communications on electronic devices such as smartphones, tablet computers, and personal computers and it is the most popular texting application in Thailand) (84.29\%). In addition, participants also 
Table 1

Demographic information of the smartphone users who had musculoskeletal disorders $(n=643)$

\begin{tabular}{|c|c|c|c|}
\hline Characteristics & $n(\%)$ & Mean \pm SD & Min-Max \\
\hline \multicolumn{4}{|l|}{$\overline{\operatorname{Sex}}$} \\
\hline Male & $184(28.62)$ & & \\
\hline Female & $459(71.38)$ & & \\
\hline Age (years) & & $18.82 \pm 0.79$ & $17.00-26.00$ \\
\hline Weight (kg) & & $55.95 \pm 10.83$ & $38.00-110.00$ \\
\hline Height $(\mathrm{cm})$ & & $163.38 \pm 7.67$ & $145.00-186.00$ \\
\hline \multicolumn{4}{|l|}{ Body Mass Index $\left(\mathrm{kg} / \mathrm{m}^{2}\right)$} \\
\hline Normal & $577(89.74)$ & & \\
\hline Overweight $\left(\geq 25 \mathrm{~kg} / \mathrm{m}^{2}\right)$ & $66(10.26)$ & & \\
\hline Study hours per day (hours/day) & & $6.03 \pm 1.49$ & $1.00-12.00$ \\
\hline \multicolumn{4}{|l|}{ Hand dominance } \\
\hline Right & $561(87.25)$ & & \\
\hline Left & $69(10.73)$ & & \\
\hline Both & $13(2.02)$ & & \\
\hline \multicolumn{4}{|l|}{ Smoking behavior } \\
\hline Current smoker & $11(1.71)$ & & \\
\hline Former smoker & $29(4.51)$ & & \\
\hline Never smoked & $603(93.78)$ & & \\
\hline \multicolumn{4}{|l|}{ Drinking behavior } \\
\hline Current drinker & $64(9.95)$ & & \\
\hline Former drinker & $176(27.37)$ & & \\
\hline Never drank & $403(62.67)$ & & \\
\hline \multicolumn{4}{|l|}{ Exercise behavior } \\
\hline Currently exercise & 384 (59.72) & & \\
\hline Formerly exercise & $171(26.59)$ & & \\
\hline Never exercised & $88(13.69)$ & & \\
\hline \multicolumn{4}{|l|}{ Underlying disease } \\
\hline Yes & $117(18.20)$ & & \\
\hline No & $526(81.80)$ & & \\
\hline \multicolumn{4}{|l|}{ Musculoskeletal underlying disease } \\
\hline Yes & $11(1.71)$ & & \\
\hline No & $632(98.29)$ & & \\
\hline \multicolumn{4}{|l|}{ History of general accident } \\
\hline Yes & $75(11.66)$ & & \\
\hline No & $568(88.34)$ & & \\
\hline \multicolumn{4}{|l|}{ Suanprung stress test level } \\
\hline Mild stress & $79(12.29)$ & & \\
\hline Moderate stress & $201(31.26)$ & & \\
\hline High stress & $276(42.92)$ & & \\
\hline Severe stress & $87(13.53)$ & & \\
\hline
\end{tabular}

reported using other devices (79.63\%) especially laptops $(76.62 \%)$ which they reported they had used for the previous $6.71 \pm 3.89$ years, used $1.94 \pm 1.44$ hours per time and used $3.55 \pm 2.66$ hours per day.

\subsection{Postures assumed during smartphone use by those who reported musculoskeletal disorders}

Smartphone users described their posture during smartphone use by indicating postures assumed by various body parts from a menu, The majority of smartphone users who reported musculoskeletal disorders adopted positions of: neck flexion $(82.74 \%)$, shoulder protraction (56.61\%), elbow flexion $(65.16 \%)$, wrist and hand flexion during keying $(22.40 \%)$, wrist and hand supination to support the device $(21.62 \%)$, upper back flexion $(67.50 \%)$, lower back flexion (43.23\%), hip and thigh flexion $(37.95 \%)$, knee flexion $(67.81 \%)$ and ankle and foot neutral $(61.59 \%)$ positions during smartphone use.

\subsection{The prevalence of musculoskeletal disorders among smartphone users}

The prevalence of musculoskeletal disorders was highest in the neck $(32.50 \%)$, shoulder $26.91 \%$, upper back $20.69 \%$, wrist and hand $19.75 \%$. Musculoskeletal disorders were less prevalent in the lower back 
Table 2

Reported smartphone use data by users with musculoskeletal disorders $(n=643)$

\begin{tabular}{|c|c|c|c|}
\hline Characteristics & $n(\%)$ & Mean \pm SD & Min-Max \\
\hline \multicolumn{4}{|l|}{ Brand } \\
\hline A & $336(52.26)$ & & \\
\hline $\mathrm{B}$ & $203(31.57)$ & & \\
\hline $\mathrm{C}$ & $20(3.11)$ & & \\
\hline Others & $84(13.06)$ & & \\
\hline \multicolumn{4}{|l|}{ Model } \\
\hline A & $83(12.91)$ & & \\
\hline $\mathrm{B}$ & $81(12.60)$ & & \\
\hline $\mathrm{C}$ & $65(10.11)$ & & \\
\hline Others & $414(64.38)$ & & \\
\hline \multicolumn{4}{|l|}{ Type } \\
\hline Touch screen & $615(95.65)$ & & \\
\hline Keypad with a touch screen & $28(4.35)$ & & \\
\hline Length $(\mathrm{mm})$ & & $133.24 \pm 12.50$ & $103.70-166.90$ \\
\hline Width (mm) & & $66.99 \pm 7.32$ & 47.00-93.00 \\
\hline Thickness (mm) & & $8.28 \pm 1.28$ & $1.35-15.20$ \\
\hline Weight (g) & & $134.30 \pm 22.43$ & $75.00-326.00$ \\
\hline Screen size (inch) & & $4.46 \pm 0.69$ & $2.20-6.00$ \\
\hline $\begin{array}{l}\text { The start time until the current time } \\
\text { (years) }\end{array}$ & & $4.60 \pm 2.66$ & $0.02-15.00$ \\
\hline Usage time per time (hours) & & $1.04 \pm 1.47$ & $0.03-20.00$ \\
\hline Usage time per day (hours) & & $5.03 \pm 3.37$ & $0.08-24.00$ \\
\hline \multicolumn{4}{|l|}{ Time period } \\
\hline Morning & $11(1.71)$ & & \\
\hline Noon & $13(2.02)$ & & \\
\hline Afternoon & $28(4.35)$ & & \\
\hline Evening & $512(79.63)$ & & \\
\hline Others (such as before bed) & $79(12.29)$ & & \\
\hline \multicolumn{4}{|l|}{ Rest time } \\
\hline Yes & $602(93.62)$ & & \\
\hline No & $41(6.38)$ & & \\
\hline \multicolumn{4}{|l|}{ Main hand } \\
\hline Only right side & 303 (47.12) & & \\
\hline Only left side & $31(4.82)$ & & \\
\hline Both sides & 309 (48.06) & & \\
\hline \multicolumn{4}{|l|}{ Data entry method } \\
\hline $\begin{array}{l}\text { Held by both hands while entering } \\
\text { data using both thumbs }\end{array}$ & $356(55.37)$ & & \\
\hline $\begin{array}{l}\text { Held by both hands while entering } \\
\text { data using right thumb }\end{array}$ & $113(17.57)$ & & \\
\hline $\begin{array}{l}\text { Held by both hands while entering } \\
\text { data using left thumb }\end{array}$ & $11(1.71)$ & & \\
\hline $\begin{array}{l}\text { Held by right hand while entering } \\
\text { data using right thumb }\end{array}$ & $136(21.15)$ & & \\
\hline Others & $27(4.20)$ & & \\
\hline \multicolumn{4}{|l|}{ Posture in use } \\
\hline Sitting & 447 (69.52) & & \\
\hline Standing & $9(1.40)$ & & \\
\hline Walking & $3(0.47)$ & & \\
\hline Lying & $182(28.30)$ & & \\
\hline Others & $2(0.31)$ & & \\
\hline \multicolumn{4}{|l|}{ Purpose of use } \\
\hline $\begin{array}{l}\text { Social network (such as Facebook, } \\
\text { Line application) }\end{array}$ & $542(84.29)$ & & \\
\hline News & $26(4.04)$ & & \\
\hline Data searching & $16(2.49)$ & & \\
\hline $\begin{array}{l}\text { Entertainment (such as TV, Clip, } \\
\text { Movies and radio) }\end{array}$ & $51(7.93)$ & & \\
\hline Others (such as game playing) & $8(1.24)$ & & \\
\hline
\end{tabular}


Table 2

(Continued)

\begin{tabular}{lccc}
\hline Characteristics & $n(\%)$ & Mean \pm SD & Min-Max \\
\hline Other devices using & $\mathbf{5 1 2}(\mathbf{7 9 . 6 3})$ & & \\
$\quad$ Yes & $131(20.37)$ & & \\
$\quad$ No & $1(0.20)$ & & \\
Other deices type & $\mathbf{3 9 0}(\mathbf{7 6 . 6 2})$ & & \\
$\quad$ Mouse & $54(10.61)$ & & $0.10-18.00$ \\
$\quad$ Laptop & $64(12.57)$ & & \\
$\quad \begin{array}{l}\text { Personal computer } \\
\text { Tablet }\end{array}$ & & $6.71 \pm 3.89$ & $0.17-10.00$ \\
$\begin{array}{l}\text { The start time until the current time } \\
\text { of other devices (years) }\end{array}$ & & & \\
Usage time per time of other devices & & & \\
$\quad$ (hours) & & $3.94 \pm 1.44$ & \\
Usage time per day of other devices & & & \\
$\quad$ (hours) & & & \\
\hline
\end{tabular}

$17.26 \%$, the hip and thigh $9.80 \%$, the knee $7.31 \%$, the ankle and foot $6.69 \%$ and the elbow $4.97 \%$.

\subsection{Relationship between neck disorders and associated factors}

The relationship between neck disorders and associated factors is presented in Table 3. This study found that personal factors like smoking (OR 8.99, 95\% CI 1.88-42.87) and ergonomic factors like neck flexion posture (OR 2.44, 95\% CI 1.21-4.90) were factors associated with the occurrence of neck musculoskeletal disorders in smartphone users.

\section{Discussion}

The purpose of this study was to determine associations between neck flexion postures and neck disorders among smartphone users. The current study found that smoking and neck flexion posture were associated with the occurrence of neck musculoskeletal disorders in the smartphone users.

Smoking is an important individual risk factor for neck musculoskeletal disorders [23]. It is clear that cigarette smoking has deleterious effects on the musculoskeletal system [24]. Two recent systematic reviews published by Hogg-Johnson et al. [25] and Côté et al. [26] evaluated the determinants of neck pain. The former found evidence that exposure to passive smoking in adolescents increased the risk of neck pain. The latter review summarized that smoking increased the risk of neck pain among the working population $[25,26]$. The current study is the first to show smoking is a factor associated with neck disorders in smartphone users. The odds ratio for this was high because there were 11 participants who identified themselves as current smokers and 9 of them had musculoskeletal disorders in the sample of 643 participants. The Khon Kaen University is a non-smoking campus which may account for the low number of smokers in the current study. In the future, it would be useful to study a specific 'smoker only' group to clearly confirm this finding. In linking smoking with neck pain, clinical and experimental studies have shown that cigarette smoking induced skeletal muscle damage due to impaired muscle metabolism, increased inflammation and oxidative stress [27]. These could be affected by the occurrence of neck pain in university student smartphone users.

Neck flexion is the most common posture smartphone users adopt when looking at their smartphone visual display terminals for long duration of time and such postures may cause musculoskeletal problems [19] especially in the neck region [5]. Kim et al. [28] studied the influence of the duration of smartphone use on cervical and lumbar spine flexion angles and reposition error in the cervical spine in 18 healthy smartphone users. They measured the kinematics of the upper and lower cervical and lumbar spine flexion angles and the reposition error of the upper and lower cervical spine after 3 seconds (s) and $300 \mathrm{~s}$ (five minutes) of smartphone use in sitting. They reported that the flexion angles of the lower cervical and lumbar spine and the reposition error in the upper and lower cervical spine were significantly increased after $300 \mathrm{~s}$ of smartphone use $(p<0.05)$. However, the flexion angle of the upper cervical spine was not significantly different between the $3 \mathrm{~s}$ and $300 \mathrm{~s}$ smartphone of use $(p>0.05)$. These findings suggest that prolonged 
Table 3

The relationship between neck disorders and associated factors

\begin{tabular}{|c|c|c|}
\hline \multirow[t]{2}{*}{ Characteristics } & \multicolumn{2}{|c|}{ Neck } \\
\hline & $\overline{\text { ORcrude }(95 \% \mathrm{CI})}$ & ORadjust (95\% CI) \\
\hline \multicolumn{3}{|l|}{$\overline{\operatorname{Sex}}$} \\
\hline Male & 1.00 & \\
\hline Female & $1.07(0.74-1.54)$ & - \\
\hline \multicolumn{3}{|l|}{ Age (years) } \\
\hline$<18.82 \pm 0.79$ & 1.00 & \\
\hline$\geq 18.82 \pm 0.79$ & $0.76(0.54-1.08)^{*}$ & - \\
\hline \multicolumn{3}{|l|}{ Weight $(\mathrm{kg})$} \\
\hline$<55.95 \pm 10.83$ & 1.00 & \\
\hline$\geq 55.95 \pm 10.83$ & $0.85(0.61-1.19)$ & - \\
\hline \multicolumn{3}{|l|}{ Height $(\mathrm{cm})$} \\
\hline$<163.38 \pm 7.67$ & 1.00 & \\
\hline$\geq 163.38 \pm 7.67$ & $0.90(0.65-1.27)$ & - \\
\hline \multicolumn{3}{|l|}{ Body Mass Index $\left(\mathrm{kg} / \mathrm{m}^{2}\right)$} \\
\hline Normal & 1.00 & \\
\hline Overweight $\left(\geq 25 \mathrm{~kg} / \mathrm{m}^{2}\right)$ & $0.62(0.35-1.11)^{*}$ & $0.57(0.31-1.05)$ \\
\hline \multicolumn{3}{|c|}{ Study hours per day (hours/day) } \\
\hline$<6$ & 1.00 & \\
\hline$\geq 6$ & $1.26(0.86-1.86)^{*}$ & - \\
\hline \multicolumn{3}{|l|}{ Hand dominance } \\
\hline Other & 1.00 & \\
\hline Right & $1.11(0.68-1.83)$ & - \\
\hline \multicolumn{3}{|l|}{ Smoking behavior } \\
\hline No & 1.00 & \\
\hline Yes & $9.72(2.34)^{*}$ & $\left.8.99(1.88-42.87)^{\#}\right)$ \\
\hline \multicolumn{3}{|l|}{ Drinking behavior } \\
\hline No & 1.00 & \\
\hline Yes & $1.28(0.75-2.17)$ & - \\
\hline \multicolumn{3}{|l|}{ Exercise behavior } \\
\hline Yes & 1.00 & - \\
\hline No & $1.25(0.90-1.76)^{*}$ & \\
\hline \multicolumn{3}{|l|}{ Underlying disease } \\
\hline No & 1.00 & \\
\hline Yes & $1.20(0.79-1.83)$ & - \\
\hline \multicolumn{3}{|c|}{ Musculoskeletal underlying disease } \\
\hline No & 1.00 & \\
\hline Yes & $1.74(0.56-5.46)$ & - \\
\hline \multicolumn{3}{|l|}{ History of general accident } \\
\hline No & 1.00 & \\
\hline Yes & $1.69(1.00-2.87)^{*}$ & $1.54(0.89-2.68)$ \\
\hline \multicolumn{3}{|l|}{ Suanprung stress test level } \\
\hline Mild-moderate stress & 1.00 & \\
\hline High-severe stress & $1.26(0.90-1.76)^{*}$ & - \\
\hline \multicolumn{3}{|l|}{ Brand } \\
\hline Other brands & 1.00 & \\
\hline Brand A & $0.99(0.69-1.34)$ & - \\
\hline \multicolumn{3}{|l|}{ Model } \\
\hline Other models & 1.00 & \\
\hline Model A & $1.09(0.66-1.77)$ & - \\
\hline Type & & \\
\hline Keypad & 1.00 & \\
\hline Touch screen & $1.01(0.46-2.24)$ & - \\
\hline Length (mm) & & \\
\hline$<133.24 \pm 12.50$ & 1.00 & \\
\hline$\geq 133.24 \pm 12.50$ & $0.90(0.64-1.25)$ & - \\
\hline Width (mm) & & \\
\hline$<66.99 \pm 7.32$ & 1.00 & \\
\hline$\geq 66.99 \pm 7.32$ & $0.90(0.64-1.26)$ & $0.57(0.31-1.05)$ \\
\hline
\end{tabular}


Table 3

(Continued)

\begin{tabular}{|c|c|c|}
\hline \multirow[t]{2}{*}{ Characteristics } & \multicolumn{2}{|c|}{ Neck } \\
\hline & $\overline{\text { ORcrude }(95 \% \mathrm{CI})}$ & ORadjust (95\% CI) \\
\hline \multicolumn{3}{|l|}{ Thickness (mm) } \\
\hline$<8.28 \pm 1.28$ & 1.00 & \\
\hline$\geq 8.28 \pm 1.28$ & $1.21(0.87-1.69)$ & - \\
\hline \multicolumn{3}{|l|}{ Weight $(\mathrm{g})$} \\
\hline$<134.30 \pm 22.43$ & 1.00 & \\
\hline$\geq 134.30 \pm 22.43$ & $1.01(0.72-1.40)$ & - \\
\hline \multicolumn{3}{|l|}{ Screen size (inch) } \\
\hline$<5$ & 1.00 & \\
\hline$\geq 5$ & $0.93(0.66-1.34)$ & $8.99(1.88-42.87)$ \\
\hline \multicolumn{3}{|c|}{ The start time until the current time (years) } \\
\hline$<4.60 \pm 2.66$ & 1.00 & \\
\hline$\geq 4.60 \pm 2.66$ & $1.08(0.78-1.51)$ & - \\
\hline \multicolumn{3}{|c|}{ Usage time per time (hours) } \\
\hline$<1$ & 1.00 & \\
\hline$\geq 1$ & $0.87(0.62-1.21)$ & - \\
\hline \multicolumn{3}{|c|}{ Usage time per day (hours) } \\
\hline$<6$ & 1.00 & \\
\hline$\geq 6$ & $1.14(0.82-1.60)$ & - \\
\hline \multicolumn{3}{|l|}{ Time period } \\
\hline Other time periods & 1.00 & \\
\hline Evening & $0.67(0.45-1.00)^{*}$ & - \\
\hline \multicolumn{3}{|l|}{ Rest time } \\
\hline Yes & 1.00 & \\
\hline No & $0.65(0.32-1.34)$ & - \\
\hline \multicolumn{3}{|l|}{ Main hand } \\
\hline Both sides & 1.00 & \\
\hline Only one side & $0.98(0.71-1.36)$ & - \\
\hline \multicolumn{3}{|l|}{ Data entry method } \\
\hline Hold both sides & 1.00 & \\
\hline Hold only one side & $0.83(0.56-1.22)$ & - \\
\hline \multicolumn{3}{|l|}{ Posture in use } \\
\hline Other postures & 1.00 & \\
\hline Sitting & $0.95(0.67-1.37)$ & - \\
\hline \multicolumn{3}{|l|}{ Purpose of use } \\
\hline Other purposes & 1.00 & \\
\hline Social network & $1.39(0.86-2.22)^{*}$ & - \\
\hline \multicolumn{3}{|l|}{ Other devices using } \\
\hline No & 1.00 & \\
\hline Yes & $1.28(0.84-1.96)^{*}$ & - \\
\hline \multicolumn{3}{|l|}{ Other devices type } \\
\hline Other devices & 1.00 & \\
\hline Laptop & $1.17(0.76-1.81)$ & - \\
\hline \multicolumn{3}{|c|}{ The start time until to current time of other devices (year) } \\
\hline$<6.71 \pm 3.89$ & 1.00 & \\
\hline$\geq 6.71 \pm 3.89$ & $0.90(0.65-1.26)$ & - \\
\hline \multicolumn{3}{|c|}{ Using time per time of other devices (hour) } \\
\hline$<1.94 \pm 1.44$ & 1.00 & \\
\hline$\geq 1.94 \pm 1.44$ & $1.00(0.71-1.40)$ & - \\
\hline \multicolumn{3}{|c|}{ Using time per day of other devices (hour) } \\
\hline$<3.55 \pm 2.66$ & 1.00 & \\
\hline$\geq 3.55 \pm 2.66$ & $1.10(0.79-1.52)$ & - \\
\hline \multicolumn{3}{|l|}{ Neck posture } \\
\hline Neutral & 1.00 & \\
\hline Flexion & $1.72(0.95-3.12)^{*}$ & $\left.2.44(1.21-4.90)^{\#}\right)$ \\
\hline
\end{tabular}

Note: * Significant at the $P$-value $<0.2$ level was including into the model of logistic regression, "Significant at the $P$-value $<0.05$ level.

use of smartphones can induce changes in cervical and lumbar spine posture and proprioception in the cervical spine [28].
Park et al. [14] evaluated two groups of 10 healthy Korean student smartphone users based on the length of time spent on their smartphones. The researchers 
categorized the two groups into 'heavy' smartphone, defined as those who spent 5.4 hours a day on their smartphone, compared to a 'control' group who spent an average of 4.1 hours a day on their smartphone. The researchers measured participant craniovertebral angle, head position angle, pain threshold of the sternocleidomastoid and upper trapezius muscles, and presence of depression. They found significant differences between the groups in the pain threshold of the sternocleidomastoid and upper trapezius muscles, head position angle, and depression $(p<0.05)$, but not in the craniovertebral angle. Based on the results, their study showed that 'heavy' smartphone use may produce considerable stresses on the cervical spine, thus changing the cervical curve and pain threshold of the muscles around the neck. Smartphones could also cause negative effects on a person's psychological status, such as depression [14].

Lee et al. [5] assessed posture during smartphone use in 18 participants in a laboratory setting. Their measurements included the amount and range of head flexion of smartphone users, head forward flexion angle while they were conducing three common smartphone tasks (text messaging, web browsing, video watching) while sitting and standing. They found that participants maintained head flexion of $33^{\circ}-45^{\circ}$ from vertical when using the smartphone. The head flexion angle was significantly larger $(p<0.05)$ for texting than for the other tasks, and significantly larger while sitting than while standing. Their study results suggest that texting, which is one of the most frequently used app categories of smartphone, could be a main contributing factor to the occurrence of neck pain of 'heavy' smartphone users [5].

Ning et al. [29] also evaluated the neck extensor muscle activities and the kinematics of the cervical spine during the operation of a touchscreen tablet and a smartphone in 14 participants. Participants of this study maintained significantly increased neck flexion angle when operating a smartphone $\left(44.7^{\circ}\right)$, with the mobile devices set on a table $\left(46.4^{\circ}\right)$, and while performing a typing task $\left(45.6^{\circ}\right)$ [23]. This study had apparently shown that during smartphone use, smartphone users also maintained their head flexion in various angles conforming to Lee et al. [13]. They also demonstrated that the magnitude of neck flexion was affected by the size of the screen, device location and the tasks performed [29]. Task influenced cervical spine posture with the highest cervical flexion occurring while completing a simulated data entry task [30]. Awkward posture like neck flexion refers to positions of the body that deviate significantly from the neutral position while tasks are being performed and it is the primary ergonomic risk factor for developing musculoskeletal discomfort [31]. In addition, elevated neck muscle activities were observed while holding mobile devices in hand (vs. putting them on a table) and elevated neck muscle activities also were observed while performing typing and gaming tasks (vs. reading task) [29]. These occurrences could be a main associated factor to the occurrence of neck pain.

Hansraj [32] assessed stresses on the cervical spine caused by posture and position of the head and reported that the weight taken by the spine dramatically increases when flexing the head forward at varying degrees. Loss of the natural curve of the cervical spine leads to incrementally increased stresses about the cervical spine [32].

In summary, all of the reasons above support the association we found in our study; that is, neck flexion postures in smartphone users are associated with the occurrence musculoskeletal disorders of the neck.

Our study is the first to examine stress in relation to neck disorders in smartphone users, and we found no association between stress and smartphone use. Previous studies of psychosocial factors revealed anxiety and depression to be higher in smartphone users $[12,14]$ but we are not able to comment on these individual psychosocial factors. Rather, the Suanprung Stress Test - 20 that we used in our study provides a measure of stress because this test is appropriate for Thai student and adulthood [33].

Our study found the average size of smartphone liquid crystal displays was $4.46 \pm 0.69$ inches which is smaller than the average size of smartphones reported in previous studies [9]. It is possible that smaller screen size may relate to different neck postures to improve vision, because smaller screens will cause a deeper bending of the neck to reduce the distance between the eyes and the screen, as well as increase the clarity of vision. The deeper neck bending could be due to elevated neck muscle activities, and this will affect neck pain respectively. Mobile devices with larger screen sizes are preferable from the MSD prevention perspective. However, larger screen sizes may also increase the weight of the device, which could introduce fatigue to arm and shoulder muscles when holding these devices for prolonged periods of time [29]. And this remains to be tested in future studies. It is interesting to note that most participants in this study held their smartphones with both hands, which is a good ergonomic for smartphone users. Holding a smartphone with 
one hand presents a higher risk for a musculoskeletal lesion, as compared with holding it with both hands [34].

Regarding of the implication of this study, the findings reveal an important information of an association between intensive smartphone use and the occurrence of neck disorders. Additionally, the information may be used to develop prevention measure and health promotion initiatives that aim to decrease neck flexion and smoking to address the risk of neck disorders associated with smartphone users.

The current study has some limitations. A general limitation of cross-sectional studies is that they do not show cause and effect [35]; however, this method was useful as a starting point to gauge smartphone use and associated symptoms in the university student population. Our study also did not examine some characteristics of daily smartphone use reported in other studies (e.g. number of text messages and neck postures). Furthermore, as our sample consisted of only young people we cannot compare differences between younger and older age groups as previous studies have. Additionally, it should be noted that a self-administered questionnaire increases the risk of response bias [9]. In future studies we suggest participants should be included from beyond the university student sector, and a cohort with more smoking smartphone users should be studied to confirm our finding of smoking as an associated factor.

\section{Conclusion}

Individual factor of smoking and ergonomic factor of the neck flexion posture were both associated with the occurrence of neck musculoskeletal disorders in smartphone users in the present study. To the best of our knowledge, this is the first study which has demonstrated that neck disorders in smartphone users are associated with neck flexion postures and smoking. The current data suggests that neck disorders in smartphone users can be reduced through measures that aim to decrease neck flexion and smoking.

\section{Acknowledgments}

We would like to sincerely thank the participants involved in this study. Special thanks to the Research Center in Back, Neck, Other Joint Pain and Human Performance (BNOJPH) Fund, Khon Kaen University, Thailand, for supporting our study and Mr.
Stephen Skyles for improving the readability of our manuscript in English.

\section{Conflict of interest}

None to report.

\section{References}

[1] Ericsson. Ericsson Mobility Report November 2015: Ericsson; 2015 [updated 2015 November cited 10 February 2016]. Available from: http://www.ericsson.com/res/docs/ 2015/mobility-report/ericsson-mobility-report-nov-2015. pdf

[2] eMarketer. 2 Billion Consumers Worldwide to Get Smart (phones) by 2016; eMarketer 2014 [updated 2014 December 11 cited 30 May 2016]. Available from: http://www.emarketer.com/Article/2-BillionConsumers-Worldwide-Smartphones-by-2016/1011694

[3] Han YS, Choi JK, Bo HH, Go SM, Yoon SH, Ji YG. A study on elderly for improvement of usability on smart phone. Journal of Society for e-Business Studies. 2012;17:39-52.

[4] Lee JH, Seo KC. The comparison of cervical repositioning errors according to smartphone addiction grades. Journal of Physical Therapy Science. 2014;26(4):595-98.

[5] Lee SJ, Kang H, Shin G. Head flexion angle while using a smartphone. Ergonomics. 2015;58(2):220-26.

[6] Kim MS. Influence of neck pain on cervical movement in the sagittal plane during smartphone use. Journal of Physical Therapy Science. 2015;27:15-17.

[7] Samaei SE, Tirgar A, Khanjani N, Mostafaee M, Bagheri Hosseinabadi M. Effect of personal risk factors on the prevalence rate of musculoskeletal disorders among workers of an Iranian rubber factory. Work. 2017;57(4): 547-53.

[8] Eom SH, Choi SY, Park DH. An empirical study on relationship between symptoms of musculoskeletal disorders and amount of smartphone usage. Journal of the Korea Safety Management and Science. 2013;15(2):113-15.

[9] Kim HJ, Kim JS. The relationship between smartphone use and subjective musculoskeletal symptoms and university students. Journal of Physical Therapy Science. 2015;27:575-79.

[10] The department of rehabilitation sciences of the Hong Kong polytechnic university and the Hong Kong physiotherapy association. Health effects of using portable electronic devices studied; ScienceDaily 2013 [updated 2013 September 5 cited 6 January 2014]. Available from: http://www. polyu.edu.hk/cpa/text/index.php?search=\&press_section=\& press_category $=$ All $\&$ press_date $=\&$ mode $=$ pressrelease $\&$ Itemid=223\&option=com_content\&page $=1 \&$ order $=$ desc\&orderby=news_date \&press_id $=2606$

[11] Bair B, Gama M, Toberman M. Prevalence and Risk Factors for Neck and Shoulder Musculoskeletal Symptoms in Users of Touch-Screen Tablet Computers [doctoral project]. [Las Vegas (USA)]: University of Nevada. 2015.

[12] Hwang KH, Yoo YS, Cho OH. Smartphone overuse and upper extremity pain, anxiety, depression, and interpersonal relationships among college students. The Journal of the Korea Contents Association. 2012;12(10):365-75. 
[13] Lee JI, Song HS. The Correlation Analysis between Hours of Smartphone Use and Neck Pain in the Gachon University Students. The Acupuncture 2015 [updated 2015 June 20 cited 1 April 2016]. Available from: http://www. theacupuncture.org/upload/acupunct_31-2-99_109-10.pdf

[14] Park JH, Kim JH, Kim JG, Kim KH, Kim NK, Choi IW, et al. The effects of heavy smartphone use on the cervical angle, pain threshold of neck muscles and depression. Advanced Science and Technology Letters. 2015;91:12-7.

[15] Sim J, Lacey RJ, Lewis M. The impact of workplace risk factors on the occurrence of neck and upper limb pain: A general population study. BMC Public Health. 2006;6:234.

[16] Yu IT, Wong TW. Musculoskeletal problems among VDU workers in a Hong Kong bank. Occup Med. 1996;46(4): 275-80.

[17] Cagnie B, Danneels L, VanTiggelen D, DeLoose V, Cambier D. Individual and work related risk factors for neck pain among office workers: A cross sectional study. Eur Spine J. 2007;16(5):679-86.

[18] Ming Z, Närhi M, Siivola J. Neck and shoulder pain related to computer use. Pathophysiology. 2004;11(1):51-6.

[19] Kang JH, Park RY, Lee SJ, Kim JY, Yoon SR, Jung KI. The effect of the forward head posture on postural balance in long time computer based worker. Annals of Physical and Rehabilitation Medicine. 2012;36(1):98-104.

[20] Namwongsa S, Puntumetakul R, Eungpinithpong W, Buranruk O, Chatchawan U, Kamolrat T, et al. Validity of the musculoskeletal system health status questionnaire in smartphone users. 1st National Conference on Physical Activity 1. 2015;1:35-47.

[21] Kongsomboon K. Stress in the workplace: A report at the faculty of medicine, srinakharinwirot University. Songkla Med J. 2010;28(6):329-37.

[22] Saetan O. Health status in musculoskeletal system among northeastern construction workers with temporary migration [Master thesis]. [Khon Kaen (TH)]: Khon Kaen University. 2007.

[23] da Costa BR, Vieira ER. Risk factors for work-related musculoskeletal disorders: A systematic review of recent longitudinal studies. American Journal of Industrial Medicine. 2010;53(3):253-323.

[24] Abate M, Vanni D, Pantalone A, Salini V. Cigarette smoking and musculoskeletal disorders. Muscles Ligaments Tendons J. 2013;3(2):63-9.
[25] Hogg-Johnson S, van der Velde G, Carroll LJ, Holm LW, Cassidy JD, Guzman J, et al. The burden and determinants of neck pain in the general population: Results of the Bone and Joint Decade 2000-2010 Task Force on Neck Pain and Its Associated Disorders. Spine (Phila Pa 1976). 2008;33(4 Suppl):S39-51.

[26] Côté P, van der Velde G, Cassidy JD, Carroll LJ, HoggJohnson S, Holm LW, et al. The burden and determinants of neck pain in workers: Results of the Bone and Joint Decade 2000-2010 Task Force on Neck Pain and Its Associated Disorders. Spine (Phila Pa 1976). 2008;33(4 Suppl): S60-74.

[27] Rom O, Kaisari S, Aizenbud D, Reznick AZ. Identification of possible cigarette smoke constituents responsible for muscle catabolism. J Muscle Res Cell Motil. 2012;33 (3-4):199-208.

[28] Kim YG, Kang MH, Kim JW, Jang JH, Oh JS. Influence of the duration on smartphone usage on flexion angles of the cervical and lumbar spine and on reposition error in the cervical spine. Phys Ther Korea. 2013;20(1):10-7.

[29] Ning XP, Huang YP, Hu BY, Nimbarte AD. Neck kinematics and muscle activity during mobile device operations. International Journal of Industrial Ergonomics. 2015;48:10-5.

[30] Riddell MF, Gallagher KM, McKinnon CD, Callaghan JP. Influence of input device, work surface angle, and task on spine kinematics. Work. 2016;55(4):773-82.

[31] Aghilinejad M, Azar NS, Ghasemi MS, Dehghan N, Mokamelkhah EK. An ergonomic intervention to reduce musculoskeletal discomfort among semiconductor assembly workers. Work. 2016;54 (2):445-50.

[32] Hansraj KK. Assessment of stresses in the cervical spine caused by posture and position of the head. Surgical Technology International. 2014;25:277-9.

[33] Kongsomboon K. Stress in the workplace: A report at the faculty of medicine, Srinakharinwirot University. Songklanagarind Medical Journal. 2010;28(6):329-37.

[34] Hong JH, Lee DY, Yu JH, Kim YY, Jo YJ, Park MH, et al. Effect of the keyboard and smartphone usage on the wrist muscle activities. Journal of Convergence Information Technology. 2013;8(14):472-5.

[35] Sedgwick P. Cross sectional studies: Advantages and disadvantages. BMJ. 2014;348:g2276. 